\title{
The effect of $\mathrm{Mg}$ doping on the dielectric and tunable properties of $\mathrm{Pb}_{0.3} \mathrm{Sr}_{0.7} \mathrm{TiO}_{3}$ thin films prepared by sol-gel method
}

\author{
Xiaohua Sun • Xiuneng Li • Shuang Hou • \\ Caihua Huang · Jun Zou • Meiya Li · Tianyou Peng • \\ Xing-zhong Zhao
}

Received: 22 October 2012 / Accepted: 21 February 2013 / Published online: 6 March 2013

(c) The Author(s) 2013. This article is published with open access at Springerlink.com

\begin{abstract}
Mg}$ doped $\mathrm{Pb}_{0.3} \mathrm{Sr}_{0.7} \mathrm{TiO}_{3}$ (PST) thin films were fabricated by the sol-gel method on a $\mathrm{Pt} / \mathrm{Ti} / \mathrm{SiO}_{2} / \mathrm{Si}$ substrate. The microstructure, surface morphology, dielectric and tunable properties of PST thin films were investigated as a function of $\mathrm{Mg}$ concentration. It is found that proper $\mathrm{Mg}$ doping dramatically improves the dielectric loss (0.0088 @ $1 \mathrm{MHz}$ ), furthermore, the crystallinity, dielectric constant, and tunability of films simultaneously decrease with the increase of $\mathrm{Mg}$ content. The $2 \mathrm{~mol} \% \mathrm{Mg}$ doped PST thin film shows the highest figure of merit (FOM) value of 36.8 for its the smallest dielectric loss and upper tunability. The dependence of Rayleigh coefficient on the doping concentration was examined, which indicated that the reduction of dielectric constant and tunability of films should be related to the $\mathrm{Mg}_{\mathrm{Ti}}^{\prime \prime}-\mathrm{V}_{\mathrm{O}}^{\bullet \bullet}$ defect dipoles pinning the domain wall motion of residual polar clusters in PST.
\end{abstract}

Electronic supplementary material The online version of this article (doi:10.1007/s00339-013-7645-z) contains supplementary material, which is available to authorized users.

X.H. Sun $(\bowtie) \cdot$ X. Li $\cdot$ S. Hou $\cdot$ C. Huang $\cdot$ J. Zou

School of Mechanical and Material Engineering, Research

Institute for New Energy, China Three Gorges University,

Yichang 443002, China

e-mail: mksxh@yahoo.com.cn

X.H. Sun · M.Y. Li · T.Y. Peng · X.-z. Zhao

School of Physics, College of Chemistry and Molecular Science,

Wuhan University, Wuhan 430072, China

T.Y. Peng

e-mail: typeng@whu.edu.cn

X.-Z. Zhao

e-mail:xzzhao@whu.edu.cn

\section{Introduction}

Solid solutions of $\mathrm{Pb}_{x} \mathrm{Sr}_{1-x} \mathrm{TiO}_{3}$ (PST) thin films have drawn great attention in recent years. Its Curie temperature can be adjusted linearly from 490 to $-230{ }^{\circ} \mathrm{C}$ with increasing $\mathrm{Sr}$ content and the process temperature of PST films is relatively low. It is considered as one of the most potential candidate materials for the future tunable microwave device components, such as phase shifters, filters, varactors, delay lines, etc. [1-4]. However, significant reductions in loss at high frequencies together with the improved dielectric tunability are needed for their realization in devices.

In order to further improve the performance of PST films, many efforts have been tried in various ways. The effects of buffer layers [5], epitaxial or oriented growth [6, 7], compositionally graded films [8] and multilayered films structures [9] on the dielectric and ferroelectric properties of PST films were investigated. Besides, it has been identified that proper acceptor doping is another effective way to optimize the ferroelectric and dielectric properties of perovskite ferroelectric films. In fact, doping may be able to change the defect concentration even of defect types. Furthermore, the different defect concentration and defect types have an important effect on the electric properties of thin films. Miao et al. controlled defects in $\left(\mathrm{Ba}_{0.8} \mathrm{Sr}_{0.2}\right)\left(\mathrm{Zr}_{0.2} \mathrm{Ti}_{0.8}\right) \mathrm{O}_{3}$ films through Co acceptor doping to depress the leakage current and increase tunable properties of films [10]. In PST system, though some researches $[11,12]$ about acceptor doping have been carried out, most of them mainly focus on the effect of acceptor dopant on the dielectric loss, and the related physics mechanisms behind the element doping adjusting defect concentration and types and then changing polarization and dielectric properties still need to be explored.

In this study, Mg doped PST thin films with dopant content from 0-6 mol\% were prepared on $\mathrm{Pt} / \mathrm{Ti} / \mathrm{SiO}_{2} / \mathrm{Si}$ sub- 
strates by the sol-gel method. The microstructure and surface morphology of the Mg doped PST films were characterized by XRD and AFM. The Rayleigh law was used to characterize the effect of $\mathrm{Mg}$ as an acceptor dopant on the defects, polarization and dielectric properties of films.

\section{Experimental procedure}

$\mathrm{Mg}$ doped $\mathrm{Pb}_{0.3} \mathrm{Sr}_{0.7} \mathrm{TiO}_{3}$ thin films were prepared according to the formula $\mathrm{Pb}_{0.3} \mathrm{Sr}_{0.7}\left(\mathrm{Ti}_{1-x} \mathrm{Mg}_{x}\right) \mathrm{O}_{3}$, where $x=0,2 \%, 4 \%$ and $6 \%$, with the sol-gel method. All the films with $10 \%$ excess $\mathrm{Pb}$ were prepared using lead acetate tri-hydrate $\left[\mathrm{Pb}\left(\mathrm{CH}_{3} \mathrm{COO}\right)_{2} \cdot 3 \mathrm{H}_{2} \mathrm{O}\right]$, strontium acetate semi-hydrate $\left[\mathrm{Sr}\left(\mathrm{CH}_{3} \mathrm{COO}\right)_{2} \cdot 1 / 2 \mathrm{H}_{2} \mathrm{O}\right]$, magnesium acetate $\left[\mathrm{Mg}\left(\mathrm{CH}_{3} \mathrm{COO}\right)_{2} \cdot 4 \mathrm{H}_{2} \mathrm{O}\right]$ and titanium tetrabutoxide $\left[\mathrm{Ti}\left(\mathrm{OC}_{4} \mathrm{H}_{9}\right)_{4}\right]$ as source materials. Glacial acetic acid, deionized water and 2-methoxyethanol were selected as solvents. Formamide, acetylacetone, and ethylene glycol were added to stabilize phase, adjust the viscosity and surface tension. The concentration of the precursor solution was adjusted to $0.5 \mathrm{~mol} / \mathrm{L}$. The precursor solution was coated on the $\mathrm{Pt} / \mathrm{TiO}_{2} / \mathrm{SiO}_{2} / \mathrm{Si}$ substrates via a spin coating at a rate of $4000 \mathrm{rpm}$ for $25 \mathrm{~s}$ and then to pyrolyzed at $400{ }^{\circ} \mathrm{C}$ for $10 \mathrm{~min}$ and $480^{\circ} \mathrm{C}$ for $5 \mathrm{~min}$. The spin-coating and heattreatment procedure was repeated several times to obtain desired thickness. Finally, all films were annealed at $700{ }^{\circ} \mathrm{C}$ for $30 \mathrm{~min}$ for crystallization.

The structural and dielectric properties of Mg doped PST thin films were characterized by various techniques. X-ray diffraction (XRD) was performed for phase identification using a Ultima IV X-ray diffractometer with $\mathrm{Cu} K_{\alpha}$ radiation. The surface and roughness were observed by the SPM$9500 \mathrm{~J} 3$ atomic force microscope (AFM). The cross section and thickness of the films were examined with a JSM-7500F field emission scanning electron microscope (FE-SEM). Dielectric measurements were carried out using the metalinsulator-metal (MIM) capacitor configuration. A gold top electrode with $0.3 \mathrm{~mm}$ diameter was deposited on the film by direct current magnetron sputtering system (JGP-560). The dielectric properties were measured using Agilent 4294A precision impedance analyzer. Ferroelectric hysteresis loops (P-E) of PST thin films were characterized by a ferroelectric tester (Precision Premier Workstation, Radiant Technology, USA).

\section{Results and discussion}

Figure 1 shows the X-ray diffraction patterns of $\mathrm{Pb}_{0.3} \mathrm{Sr}_{0.7}$ $\left(\mathrm{Ti}_{1-x} \mathrm{Mg}_{x}\right) \mathrm{O}_{3}$ thin films annealed at $700{ }^{\circ} \mathrm{C}$ with different $x$. It can be noted that all crystal structures of $\mathrm{Pb}_{0.3} \mathrm{Sr}_{0.7}\left(\mathrm{Ti}_{1-x} \mathrm{Mg}_{x}\right) \mathrm{O}_{3}$ thin films are cubic perovskite

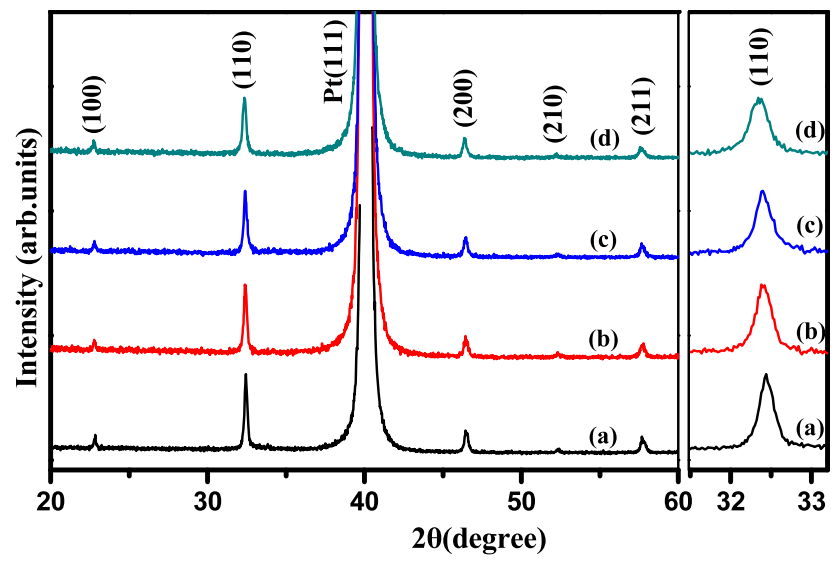

Fig. 1 X-ray diffraction patterns of the $\mathrm{Pb}_{0.3} \mathrm{Sr}_{0.7}\left(\mathrm{Ti}_{1-x} \mathrm{Mg}_{x}\right) \mathrm{O}_{3}$ thin films annealed at $700{ }^{\circ} \mathrm{C}$ with different $x$ : (a) $x=0$, (b) $x=2 \%$, (c) $x=4 \%$, , (d) $x=6 \%$

phase with no evidence of secondary phase formation and show no preferred orientation. Furthermore, the diffraction peaks shifted towards low angle gradually with the increase in $x$, which implies that the dopants have entered the unitcell maintaining the perovskite structure of solid solution. The change in the peak position should be ascribed to the substitution of $\mathrm{Ti}^{4+}$ by $\mathrm{Mg}^{2+}$ ions. The ionic radius of $\mathrm{Mg}^{2+}(0.720 \AA)$ in the 6-fold coordination is larger than that of $\mathrm{Ti}^{4+}(0.605 \AA)$ in the 6-fold coordination [13], which leads to expansion of the crystal cells. In addition, the intensity of $\mathrm{Pb}_{0.3} \mathrm{Sr}_{0.7}\left(\mathrm{Ti}_{1-x} \mathrm{Mg}_{x}\right) \mathrm{O}_{3}$ thin films reduced slightly with increasing $\mathrm{Mg}$ content, which demonstrates that the crystallinity and/or grain size of $\mathrm{Mg}$ doped samples decreases. The shift of peak position and the reduction in crystallization and/or grain size by $\mathrm{Mg}$ dopant are in agreement with the results reported in other literature [14-16].

Figure 2 shows the surface morphology of $\mathrm{Pb}_{0.3} \mathrm{Sr}_{0.7}$ $\left(\mathrm{Ti}_{1-x} \mathrm{Mg}_{x}\right) \mathrm{O}_{3}$ thin films analyzed by AFM. As shown in Fig. 2, all the AFM images show granular microstructure. The surface root-mean-square (RMS) roughness values of $\mathrm{Pb}_{0.3} \mathrm{Sr}_{0.7}\left(\mathrm{Ti}_{1-x} \mathrm{Mg}_{x}\right) \mathrm{O}_{3}$ thin films are $8.07-5.95 \mathrm{~nm}$ and the average grain sizes of films estimated using the linear intercept method are 52-62 $\mathrm{nm}$. It can be seen that the reduction of grain sizes for $\mathrm{Pb}_{0.3} \mathrm{Sr}_{0.7}\left(\mathrm{Ti}_{1-x} \mathrm{Mg}_{x}\right) \mathrm{O}_{3}$ thin films is unobtrusive, combining with the XRD analysis, which implies that Mg dopant is likely to mainly decrease the crystallinity of the PST films. The incorporation of foreign ions in thin films can lead to the lattice distortion of the perovskite phase [14] and the phase formation ability is therefore decreased with increasing dopant content, which usually results in the reduction of the crystallinity of perovskite thin films. Ming-Chieh Chiu [15], X.T. Li [14] and Sea-Fue Wang [17] et al. also reported that the $\mathrm{Mg}$ or $\mathrm{MgO}$ doping retards the crystallization of the perovskite thin films due to an increase in activation energy barrier. In addition, the crosssectional SEM images of the PST thin films are also pre- 
Fig. 2 AFM micrographs of the $\left(\mathrm{Pb}_{0.3} \mathrm{Sr}_{0.7}\right)\left(\mathrm{Ti}_{1-x} \mathrm{Mg}_{x}\right) \mathrm{O}_{3}$ thin films with different $x$ : (a) $x=0$, (b) $x=2 \%$, (c) $x=4 \%$, (d) $x=6 \%$
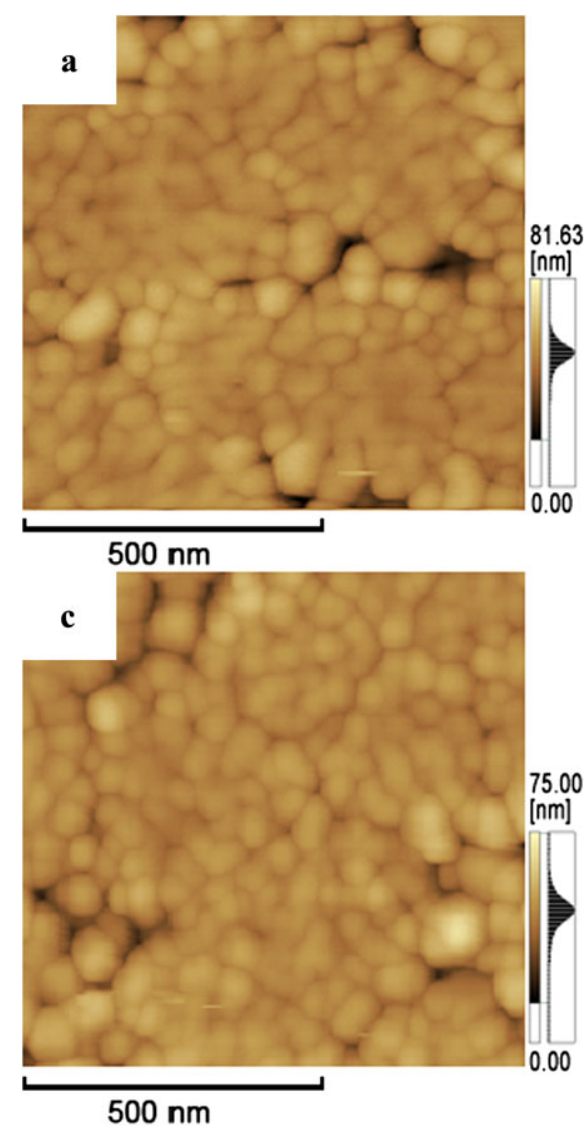
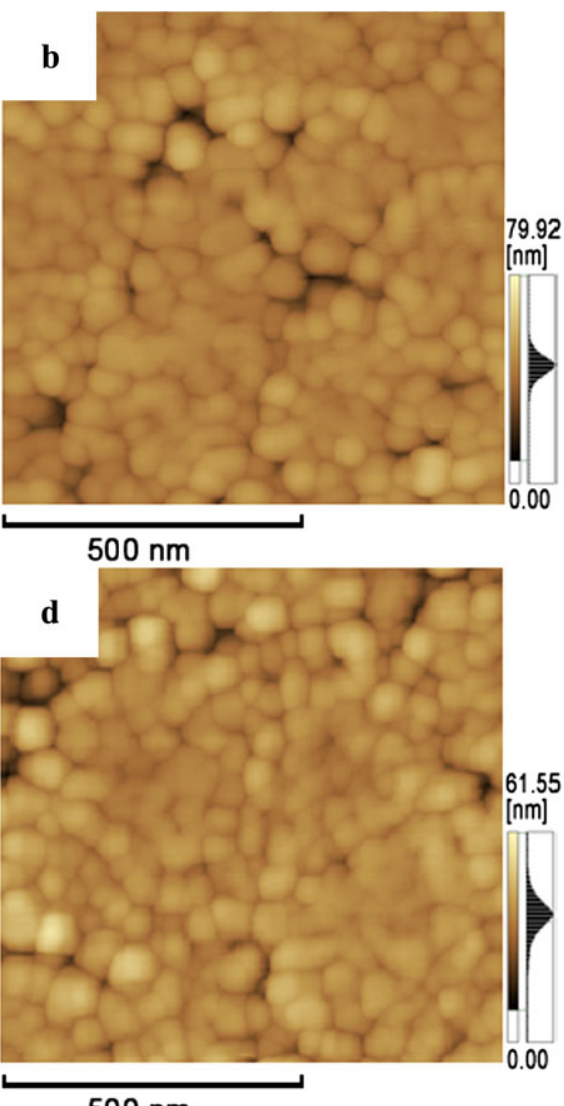

$500 \mathrm{~nm}$ sented in Fig. S1 (see Supporting Information). It can be observed that PST thin films are composed of granular grains randomly distributed throughout the film thickness and show no texture. All the PST films also exhibit uniform cross section, from which the film thickness can be estimated to be about $550 \mathrm{~nm}$.

The room-temperature dielectric constant and dielectric loss of the $\mathrm{Pb}_{0.3} \mathrm{Sr}_{0.7}\left(\mathrm{Ti}_{1-x} \mathrm{Mg}_{x}\right) \mathrm{O}_{3}$ thin films as a function of frequency for different $x$ are shown in Fig. 3 . The results were obtained using an oscillation voltage of $0.5 \mathrm{~V}$ and a frequency range of $100 \mathrm{~Hz}-1 \mathrm{MHz}$. As shown in the figure, the dielectric constant rather slowly decreases with frequency up to $1 \mathrm{MHz}$. On the other hand, the dielectric loss of all samples does not show any appreciable dispersion with frequency up to $1 \mathrm{MHz}$ indicating good interfacial characteristics between films and electrodes [18, 19]. The dielectric constant and dielectric loss of $\mathrm{Pb}_{0.3} \mathrm{Sr}_{0.7}\left(\mathrm{Ti}_{1-x} \mathrm{Mg}_{x}\right) \mathrm{O}_{3}$ thin films at $1 \mathrm{MHz}$ as a function of $\mathrm{Mg}$ content are illustrated in the inset of Fig. 3. As can be seen, the dielectric constants of the $\mathrm{Pb}_{0.3} \mathrm{Sr}_{0.7}\left(\mathrm{Ti}_{1-x} \mathrm{Mg}_{x}\right) \mathrm{O}_{3}$ thin films gradually decreased from 435 to 150 with increasing $x$ up to $6 \%$. At the same time, the dielectric loss of thin films distinctly decreased to 0.0088 and then slowly increased with the increase of $\mathrm{Mg}$ content. But all the dielectric loss of the $\mathrm{Mg}$ doped PST films is lower than that of undoped PST film.
It is reported that the dielectric properties of ferroelectric thin films are greatly influenced by microstructure, orientation, grain size and crystallization, etc. [20-22]. We know that the reduction of crystallinity and grain size of thin films all can depress the dielectric polarization and then decreases the permittivity since the volume of dielectric polarization is proportional to the crystallinity and grain size [23]. Quantitative dielectric polarization information can be obtained from the P-E hysteresis loops of $\mathrm{Pb}_{0.3} \mathrm{Sr}_{0.7}\left(\mathrm{Ti}_{1-x} \mathrm{Mg}_{x}\right) \mathrm{O}_{3}$ thin films (as shown in Fig. 4). As we can see, undoped PST thin film shows weak ferroelectricity, which should be mainly due to the presence of residual polar clusters in the paraelectric phase at temperature close to $T_{\mathrm{C}}$ [24-26]. The similar phenomenon was also reported by $\mathrm{Zhi} \mathrm{Yu}$ et al. in $\mathrm{BaTi}_{0.7} \mathrm{Zr}_{0.3} \mathrm{O}_{3}$ ceramic and X.G. Tang et al. in $(\mathrm{Ba}, \mathrm{Sr})(\mathrm{Zr}, \mathrm{Ti}) \mathrm{O}_{3}$ ferroelectric ceramics [27, 28]. With the increase of $\mathrm{Mg}$ content, the hysteresis loops of $\mathrm{Pb}_{0.3} \mathrm{Sr}_{0.7}\left(\mathrm{Ti}_{1-x} \mathrm{Mg}_{x}\right) \mathrm{O}_{3}$ films become slim and the polarization obviously decreases, which indicates the domains' reorienting or motion of residual polar clusters are gradually locked or pinned. And the remnant polarization $\left(2 P_{r}\right)$ decreases from $3.3 \mu \mathrm{C} / \mathrm{cm}^{2}$ to $0.4 \mu \mathrm{C} / \mathrm{cm}^{2}$, which is similar to the change tendency of permittivity. According to the definition of polarization in dielectric physics $\left(P=\varepsilon_{0}\left(\varepsilon_{r}-1\right) E\right.$, where $\varepsilon_{0}, \varepsilon_{r}$, and $E$ are the permittivity of vacuum, the relative dielectric permittivity of film, and the applied electrical 


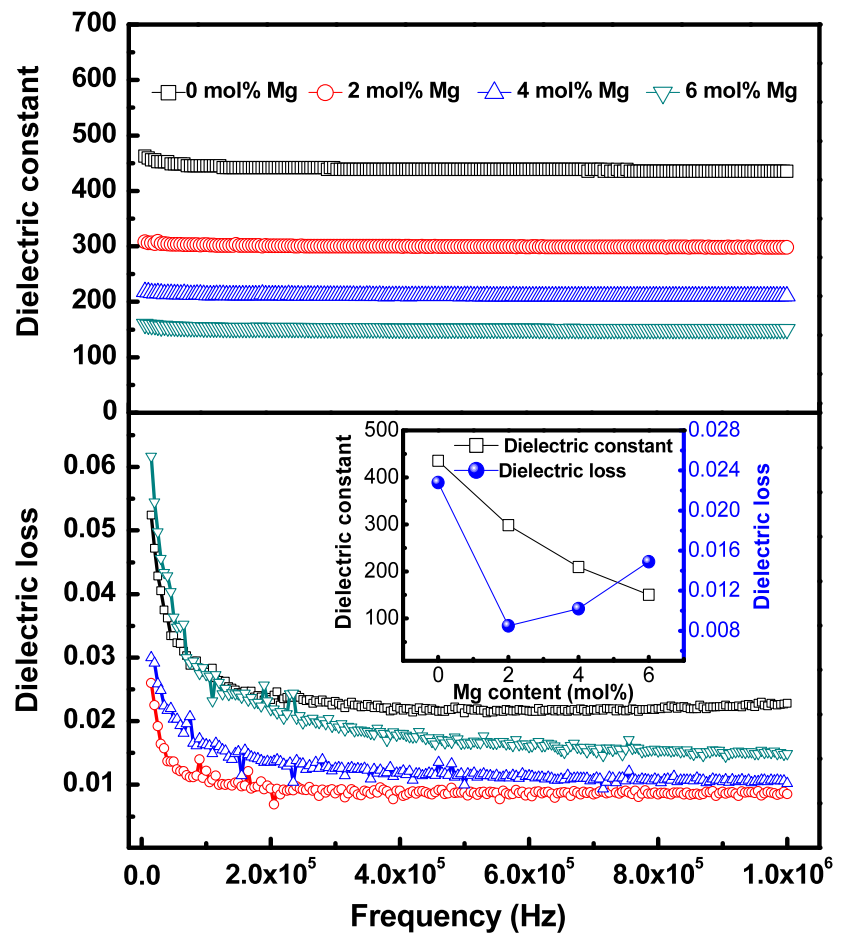

Fig. 3 Dielectric constant and dielectric loss of the $\left(\mathrm{Pb}_{0.3} \mathrm{Sr}_{0.7}\right)\left(\mathrm{Ti}_{1-x} \mathrm{Mg}_{x}\right) \mathrm{O}_{3}$ thin films as functions of frequency at room temperature. The inset shows dielectric constant and dielectric loss of $\left(\mathrm{Pb}_{0.3} \mathrm{Sr}_{0.7}\right)\left(\mathrm{Ti}_{1-x} \mathrm{Mg}_{x}\right) \mathrm{O}_{3}$ thin films as a function of $\mathrm{Mg}$ content at $1 \mathrm{MHz}$

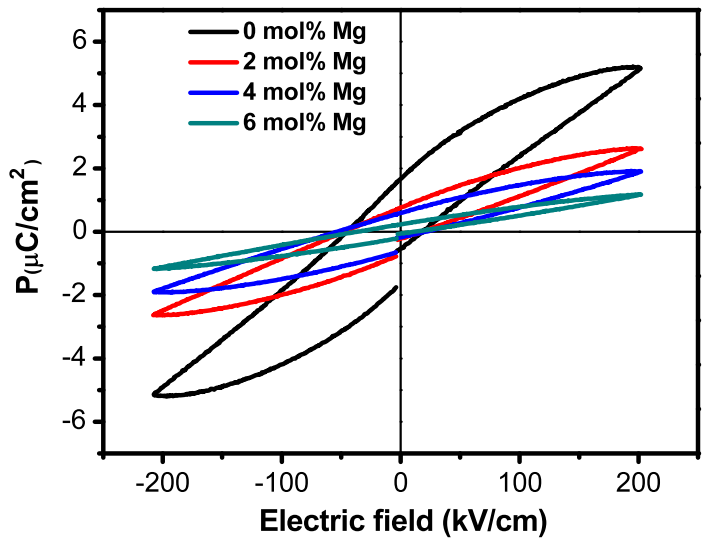

Fig. 4 The typical P-E hysteresis loops of the $\left(\mathrm{Pb}_{0.3} \mathrm{Sr}_{0.7}\right)\left(\mathrm{Ti}_{1-x} \mathrm{Mg}_{x}\right) \mathrm{O}_{3}$ thin films measured at $10 \mathrm{kHz}$ and a maximum applied field of $200 \mathrm{kV} / \mathrm{cm}$

field, respectively), we know that the weaker the polarization is, the lower the dielectric permittivity.

The dielectric property modifications produced by dopants are largely coupled to changes in the domain wall mobility. The domain wall motion contributions to the dielectric nonlinearity and polarization in subswitching fields can be described by the Rayleigh law [10, 29],

$\varepsilon=\varepsilon_{\text {init }}+\alpha E$, where $E$ is the applied AC field; $\varepsilon_{\text {init }}$ is the sum of the intrinsic lattice and reversible domain wall responses; $\alpha$ is the Rayleigh coefficient due to the irreversible displacement of domain wall. The reciprocal of Rayleigh coefficient is proportional to the concentration of defect pinning domain wall motion. Figure 5 shows the AC electric-field dependence of the dielectric constant of $\mathrm{Pb}_{0.3} \mathrm{Sr}_{0.7}\left(\mathrm{Ti}_{1-x} \mathrm{Mg}_{x}\right) \mathrm{O}_{3}$ films with different $x$ at $100 \mathrm{kHz}$. It gives a linear relationship that follows the Rayleigh law. Linear fitting the data of Fig. 5 to Eq. (1), Rayleigh coefficient $\alpha$ of $\mathrm{Pb}_{0.3} \mathrm{Sr}_{0.7}\left(\mathrm{Ti}_{1-x} \mathrm{Mg}_{x}\right) \mathrm{O}_{3}$ films is obtained and presented in Fig. 6. The Mg content dependence of the remnant polarization and dielectric constant is simultaneously presented. Noting that with increasing $\mathrm{Mg}$ content, the Rayleigh coefficient $\alpha$ of $\mathrm{Pb}_{0.3} \mathrm{Sr}_{0.7}\left(\mathrm{Ti}_{1-x} \mathrm{Mg}_{x}\right) \mathrm{O}_{3}$ films obviously reduces, i.e. the concentration of defect pinning domain wall motion increases, and the remnant polarization and the permittivity all decrease.

As we know, it is inevitable to engender some oxygen vacancies, a kind of point defect, in preparing ferroelectric thin films especially with the sol-gel method. However, oxygen vacancy should not be the defect penning domain wall motion in here. Because the concentration of oxygen vacancy cannot increase with proper increasing $\mathrm{Mg}$ content (no more than the $\mathrm{Mg}$ content required for charge balance of the intrinsic oxygen vacancy). We know from Fig. 1 that $\mathrm{Mg}^{2+}$ ions substitute for $\mathrm{Ti}^{4+}$ ions and enter PST lattices. The substitutional ions $\mathrm{Mg}_{\mathrm{Ti}}^{\prime \prime}$ with extra negative charges can compensate positive charged oxygen vacancies, which would produce defect dipoles like $\mathrm{Mg}_{\mathrm{Ti}}^{\prime \prime}-\mathrm{V}_{\mathrm{O}}^{\bullet \bullet}$. The concentration of electric defect $\mathrm{Mg}_{\mathrm{Ti}}^{\prime \prime}-\mathrm{V}_{\mathrm{O}}^{\bullet \bullet}$ will increase with increasing $\mathrm{Mg}$ content. Until the present, lots of researcher have observed some defect dipoles such as $\mathrm{Cu}_{\mathrm{Ti}}^{\prime \prime}-\mathrm{V}_{\mathrm{O}}^{\bullet \bullet}$ [30], $\mathrm{Mn}_{\mathrm{Ti}}^{\prime \prime}-\mathrm{V}_{\mathrm{O}}^{\bullet \bullet}[31]$, $\mathrm{Fe}_{\mathrm{Ti}}^{\prime}-\mathrm{V}_{\mathrm{O}}^{\bullet \bullet}[32-34], \mathrm{Fe}_{\mathrm{Zr}, \mathrm{Ti}}^{\prime}-\mathrm{V}_{\mathrm{O}}^{\bullet \bullet}$ [35-37] and $\mathrm{Cu}_{\mathrm{Zr}, \mathrm{Ti}}^{\prime \prime}-\mathrm{V}_{\mathrm{O}}^{\bullet \bullet}$ [36] and showed the alignment of defect dipoles along the direction of the spontaneous polarization by means of electron paramagnetic resonance (EPR) spectroscopy in some perovskite oxides. As is described elsewhere, dipoles may produce local electric fields and reduce the irreversible domain wall motion [36, 38]. Furthermore, the electric dipoles could be ordered under external electric field. It will, in turn, form a lower net internal field and reduce the polarization of polar clusters and then decrease the permittivity [39]. These phenomena are all consistent with the relationship of $\mathrm{Mg}$ content with the Rayleigh coefficient $(\alpha)$, the average remnant polarization $\left(2 P_{r}\right)$, and the dielectric constant $\left(\varepsilon_{r}\right)$ (as shown in Fig. 6). So, these defect dipoles $\mathrm{Mg}_{\mathrm{Ti}}^{\prime \prime}-\mathrm{V}_{\mathrm{O}}^{\bullet \bullet}$ are thought of as defects pinning domain wall motion.

In addition, because the movement of domain wall in the remanent ferroelectric clusters would produce certain loss, the dielectric loss tangent of thin films should reduce while the domain-wall movements are constrained by the defect dipoles $\mathrm{Mg}_{\mathrm{Ti}}^{\prime \prime}-\mathrm{V}_{\mathrm{O}}^{\bullet \bullet}$. The reduction in dielectric loss due to 
Fig. 5 AC electric field dependence of the dielectric constant of the

$\left(\mathrm{Pb}_{0.3} \mathrm{Sr}_{0.7}\right)\left(\mathrm{Ti}_{1-x} \mathrm{Mg}_{x}\right) \mathrm{O}_{3}$ thin films measured at $100 \mathrm{kHz}$

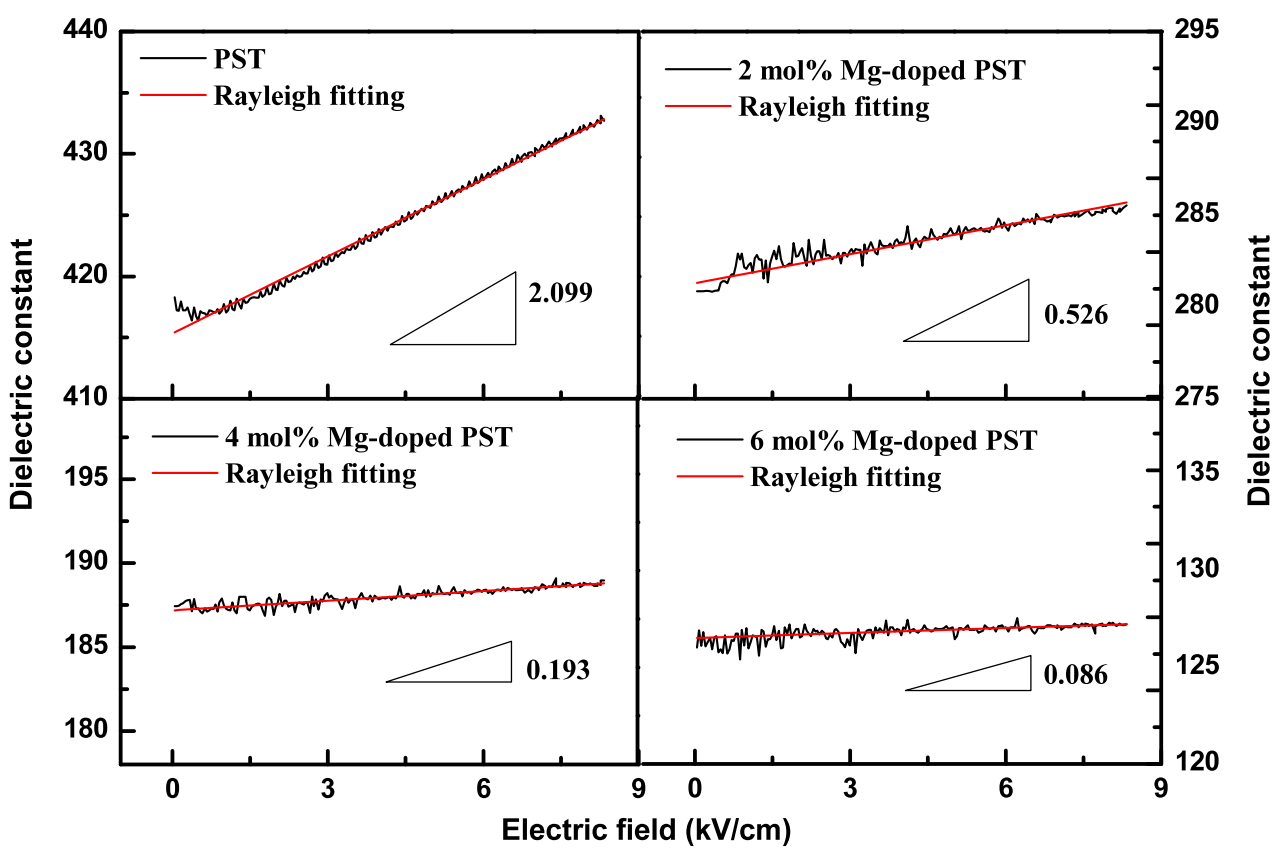

domain wall motion claimed was also reported by M. Jain [40] and M. Zhang [25] et al. However, the dielectric loss of $\mathrm{Pb}_{0.3} \mathrm{Sr}_{0.7}\left(\mathrm{Ti}_{1-x} \mathrm{Mg}_{x}\right) \mathrm{O}_{3}$ thin films does not linearly reduce with the increase of $\mathrm{Mg}$ content, which should also be related to the $\mathrm{Mg}$ content and the mechanism of acceptor doping reducing dielectric loss.

As is known, acceptor-type dopants can prevent the reduction of $\mathrm{Ti}^{4+}$ to $\mathrm{Ti}^{3+}$ by neutralizing the donor action of the oxygen vacancies in perovskite materials. The similar result has been reported by Yanhua Fan et al. by means of the X-ray photoelectron spectra (XPS) analysis [41]. Because the electrons resulting from the generation of oxygen vacancy can hop between different titanium ions and provide a mechanism for dielectric losses, the compensation for oxygen vacancy with the correct amount of acceptor dopants such as $\mathrm{Mg}^{2+}$ should, in theory, help to lower the loss tangent [42]. But if the acceptor doping ions are heavy, the oxygen vacancy required for charge balance may exceed the intrinsic oxygen vacancy, which induces the increase of dielectric loss [43]. So, before the Mg doping the content does not exceed the content of the intrinsic oxygen vacancy required for charge balance, the dielectric loss tangent of Mg doped PST thin films will dramatically decrease due to the corporate effect of proper acceptor doping and defect dipoles $\mathrm{Mg}_{\mathrm{Ti}}^{\prime \prime}-\mathrm{V}_{\mathrm{O}}^{\bullet \bullet}$ pinning domain wall motion, reducing dielectric loss. The low dielectric loss of $2 \mathrm{~mol} \% \mathrm{Mg}$ doped PST thin film should belong to this situation. While the Mg doping exceeds the correct content, the superfluous $\mathrm{Mg}$ dopant induces the increase of dielectric loss which may surpass the reduce of dielectric loss for defect dipoles $\mathrm{Mg}_{\mathrm{Ti}}^{\prime \prime}-$ $\mathrm{V}_{\mathrm{O}}^{\bullet \bullet}$ pinning domain wall motions, which makes the dielectric loss tangent of $\mathrm{Mg}$ doped thin films slightly increase.

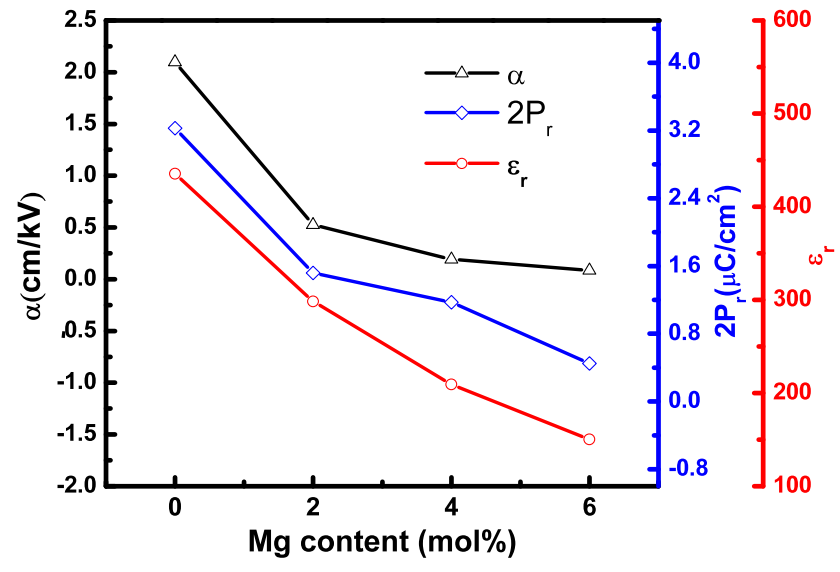

Fig. 6 The Rayleigh coefficient $(\alpha)$, the average remnant polarization $\left(2 P_{r}\right)$, and the dielectric constant $\left(\varepsilon_{r}\right)$ as a function of the Mg concentration for the $\left(\mathrm{Pb}_{0.3} \mathrm{Sr}_{0.7}\right)\left(\mathrm{Ti}_{1-x} \mathrm{Mg}_{x}\right) \mathrm{O}_{3}$ thin films

Now we explore the possible applications of these materials in tunable microwave applications. The potential of the PST material system to be used in voltage tunable devices depends on the ability to change the dielectric constant by means of an applied electric field. The evolution of the dielectric constant $\left(\varepsilon_{r}\right)$ and dielectric loss $(\tan \delta)$ of PST thin films with different $\mathrm{Mg}$ content as a function of applied DC electric fields is shown in Fig. 7. The curves were measured at room temperature and $1 \mathrm{MHz}$. As shown in Fig. 7, the relative dielectric constant and dielectric loss of the PMST thin films nonlinearly decreases with increasing applied DC field. The nonlinearity of permittivity with electric field at the paraelectric phase of the material results from anharmonic interaction of titanium ions in perovskite 


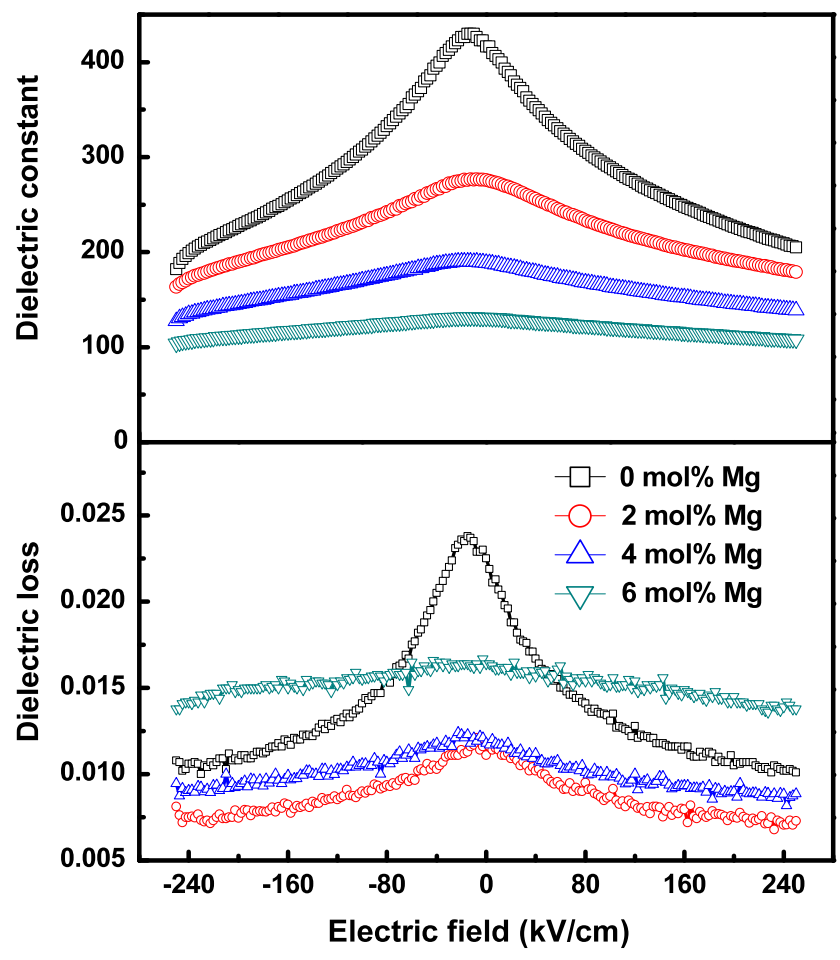

Fig. 7 Variation of the dielectric constant and loss of the $\left(\mathrm{Pb}_{0.3} \mathrm{Sr}_{0.7}\right)\left(\mathrm{Ti}_{1-x} \mathrm{Mg}_{x}\right) \mathrm{O}_{3}$ thin films with applied DC electric field at $1 \mathrm{MHz}$

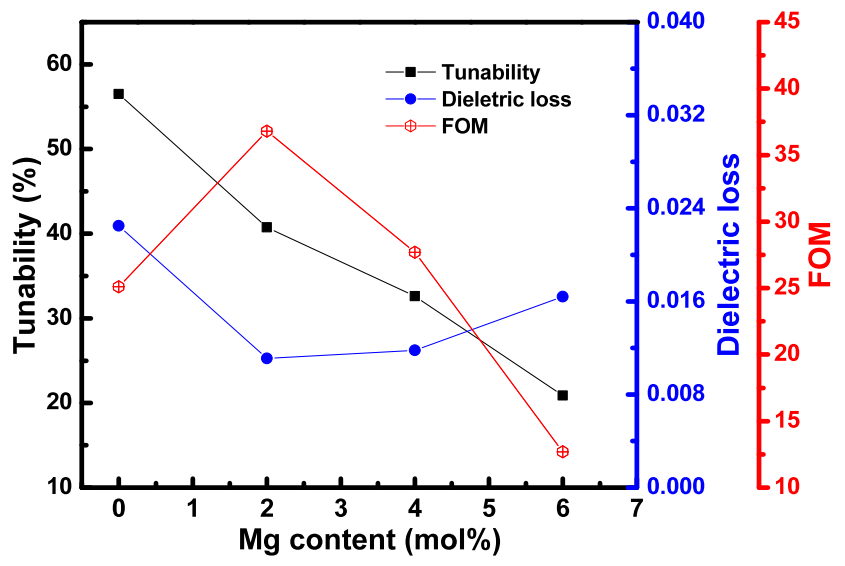

Fig. 8 Tunability, dielectric loss, and the figure of merit (FOM) of the $\left(\mathrm{Pb}_{0.3} \mathrm{Sr}_{0.7}\right)\left(\mathrm{Ti}_{1-x} \mathrm{Mg}_{x}\right) \mathrm{O}_{3}$ thin films as functions of $\mathrm{Mg}$ content at $1 \mathrm{MHz}$

structure [44]. A phenomenological equation proposed by Johnson [45] can describe the dielectric constant under the DC field which could be represented as

$\varepsilon_{r(E)} / \varepsilon_{r(0)}=1 /\left(1+\alpha \varepsilon_{r(0)}^{3} E^{2}\right)^{1 / 3}$

where $\varepsilon_{r(0)}$ and $\varepsilon_{r(E)}$ are the permittivity under zero electric field and applied electric field $E$, respectively. $\alpha$ is the anharmonic coefficient.

The tunability, dielectric loss, and figure of merit (FOM) of PSMT films as a function of $\mathrm{Mg}$ content are shown in
Fig. 8. The tunability is defined as $\left(\varepsilon_{r(0)}-\varepsilon_{r(E)}\right) / \varepsilon_{r(0)}$. The tunability of $\mathrm{Mg}$ doped PST films calculated from Fig. 7 decreases with increasing $\mathrm{Mg}$ content, which shows the similar change trend with that of dielectric constant dependence $\mathrm{Mg}$ content. The values of tunability for the $\mathrm{Pb}_{0.3} \mathrm{Sr}_{0.7}\left(\mathrm{Ti}_{1-x} \mathrm{Mg}_{x}\right) \mathrm{O}_{3}$ thin films with $x=0,2 \%, 4 \%$ and $6 \%$ are $56.5 \%, 40.7 \%, 32.6 \%$ and $20.9 \%$, respectively. Combining Eq. (2) and definition of tunability, we can deduce that tunability $=1-1 /\left(1+\alpha \varepsilon_{r(0)}^{3} E^{2}\right)^{1 / 3}$. As we can see, the tunability is a function of $\alpha \cdot \varepsilon_{r(0)}^{3}$, at given application electric field and temperature, furthermore, the $\varepsilon_{r(0)}$ plays a leading role for tunability. It can be predicted that tunability of the $\mathrm{Pb}_{0.3} \mathrm{Sr}_{0.7}\left(\mathrm{Ti}_{1-x} \mathrm{Mg}_{x}\right) \mathrm{O}_{3}$ thin films will decrease due to the obviously reduction of dielectric constant with increasing $\mathrm{Mg}$ content.

A tunable microwave circuit should take advantage of a high tunability together with a low loss factor $(\tan \delta)$. A useful figure of merit is given by FOM, tunability/tan $\delta$, which is desired to be as high as possible. As shown in Fig. 8, the FOM of the Mg doped PST thin films firstly increased and then decreased with increasing Mg content. The highest FOM value found for $2 \mathrm{~mol} \% \mathrm{Mg}$ doped PST was 36.8, which resulted from the upper tunability and the lowest loss among four samples.

\section{Conclusion}

PST thin films doped by $\mathrm{Mg}$ from 0 to $6 \mathrm{~mol} \%$ were fabricated by the sol-gel method on $\mathrm{Pt} / \mathrm{Ti} / \mathrm{SiO}_{2} / \mathrm{Si}$ substrates. The microstructure, surface morphology, dielectric and tunable properties of thin films were investigated as a function of $\mathrm{Mg}$ concentration. It is found that the $\mathrm{Mg}$ concentration in doped PST thin films has a strong influence on the material properties. The increase of $\mathrm{Mg}$ content leads to simultaneous decrease of crystallinity, dielectric constant, and tunability of films. But the dielectric loss of Mg doped PST decreases firstly and then increases with the increase of $\mathrm{Mg}$ dopant. The $2 \mathrm{~mol} \% \mathrm{Mg}$ doped PST thin film with the smallest dielectric loss and upper tunability is the best choice for tunable device applications for its highest FOM value of 36.8. The reduction of dielectric constant and tunability is mainly due to crystallinity decrease and electric dipoles $\mathrm{Mg}_{\mathrm{Ti}}^{\prime \prime}-\mathrm{V}_{\mathrm{O}}^{\bullet \bullet}$ pinning domain wall motion of residual polar clusters.

Acknowledgements This work was supported by the National Natural Science Foundation of China under grant No. 50902085.

Open Access This article is distributed under the terms of the Creative Commons Attribution License which permits any use, distribution, and reproduction in any medium, provided the original author(s) and the source are credited. 


\section{References}

1. M. Jain, N.K. Karan, R.S. Katiyar, A.S. Bhalla, F.A. Miranda, F.W.V. Keuls, Appl. Phys. Lett. 85, 275 (2004)

2. Y. Somiya, A.S. Bhalla, L.E. Cross, Int. J. Inorg. Mater. 3, 709 (2001)

3. F. Ponchel, X. Lei, D. Rémiens, G. Wang, X. Dong, Appl. Phys. Lett. 99, 172905 (2011)

4. X. Sun, H. Huang, S. Wang, M. Li, X. Zhao, Thin Solid Films 516, 1308 (2008)

5. L. Chen, M.R. Shen, L. Fang, Y. Xu, Thin Solid Films 516, 1285 (2008)

6. Y. Lin, X. Chen, S.W. Liu, C.L. Chen, J.-S. Lee, Y. Li, Q.X. Jia, A. Bhalla, Appl. Phys. Lett. 86, 142902 (2005)

7. X. Lei, D. Rémiens, F. Ponchel, C. Soyer, G. Wang, X. Dong, G.L. Brennecka, J. Am. Ceram. Soc. 94, 4323 (2011)

8. J. Zhai, X. Yao, Z. Xu, H. Chen, J. Cryst. Growth 286, 37 (2006)

9. H. Xu, M. Shen, Appl. Phys. A 84, 323 (2006)

10. J. Miao, K. Hooi Chew, Y. Jiang, Appl. Phys. Lett. 99, 232910 (2011)

11. Z. Zheng, H. Zhao, W. Weng, G. Han, N. Ma, P. Du, J. Mater. Sci.: Mater. Electron. (2010)

12. T. Li, T. Liang, G. Wu, N. Qin, D. Bao, Ferroelectrics 406, 114 (2010)

13. Q. Zhang, J. Zhai, X. Yao, J. Am. Ceram. Soc. 94, 1138 (2011)

14. X.T. Li, W.L. Huo, C.L. Mak, S. Sui, W.J. Weng, G.R. Han, G. Shen, P.Y. Du, Mater. Chem. Phys. 108, 417 (2008)

15. M.-C. Chiu, H.-C. Yao, C.-J. Huang, F.-S. Shieu, J. Appl. Phys. 102, 014110 (2007)

16. S.Y. Lee, T.Y. Tseng, Appl. Phys. Lett. 80, 1797 (2002)

17. S.-F. Wang, J.P. Chu, C.C. Lin, T. Mahalingam, J. Appl. Phys. 98, 014107 (2005)

18. M.W. Cole, C. Hubbard, E. Ngo, M. Ervin, M. Wood, R.G. Geyer, J. Appl. Phys. 92, 475 (2002)

19. M.W. Cole, P.C. Joshi, M.H. Ervin, J. Appl. Phys. 89, 6336 (2001)

20. B. Guigues, X.H. Zhu, J. Sobotka, N. Guiblin, E. Defaÿ, B. Dkhil, Appl. Phys. Lett. 95, $032902(2009)$

21. T. Liang, Thin Solid Films 517, 6689 (2009)

22. K. Verma, R. Kotnala, M. Mathpal, N. Thakur, P. Gautam, N. Negi, Mater. Chem. Phys. 114, 576 (2009)

23. M.W. Cole, W.D. Nothwang, C. Hubbard, E. Ngo, M. Ervin, J. Appl. Phys. 93, 9218 (2003)
24. J. Zhang, J. Zhai, X. Chou, J. Shao, X. Lu, X. Yao, Acta Mater. 57, 4491 (2009)

25. M. Zhang, J. Zhai, J. Zhang, H. Jiang, X. Yao, Mater. Res. Bull. 46, $1102(2011)$

26. J. Yang, J. Chu, M. Shen, Appl. Phys. Lett. 90, 242908 (2007)

27. Z. Yu, C. Ang, R. Guo, A.S. Bhalla, J. Appl. Phys. 92, 2655 (2002)

28. X.G. Tang, X.X. Wang, K.H. Chew, H.L.W. Chan, Solid State Commun. 136, 89 (2005)

29. Y. Bastani, T. Schmitz-Kempen, A. Roelofs, N. Bassiri-Gharb, J. Appl. Phys. 109, 014115 (2011)

30. R.-A. Eichel, P. Erhart, P. Träskelin, K. Albe, H. Kungl, M. Hoffmann, Phys. Rev. Lett. 100, 095504 (2008)

31. L. Zhang, E. Erdem, X. Ren, R.d.-A. Eichel, Appl. Phys. Lett. 93, 202901 (2008)

32. M.D. Drahus, P. Jakes, E. Erdem, R.-A. Eichel, Solid State Ion. 184, 47 (2011)

33. E. Erdem, K. Kiraz, M. Somer, R.-A. Eichel, J. Eur. Ceram. Soc. 30, 289 (2010)

34. H. Meštrić, R.-A. Eichel, K.-P. Dinse, A. Ozarowski, J. van Tol, L. Brunel, H. Kungl, M. Hoffmann, K. Schönau, M. Knapp, H. Fuess, Phys. Rev. B 73, 184105 (2006)

35. P. Jakes, E. Erdem, R.d.-A. Eichel, L. Jin, D. Damjanovic, Appl. Phys. Lett. 98, 072907 (2011)

36. R.-A. Eichel, J. Am. Ceram. Soc. 91, 691 (2008)

37. R.-A. Eichel, J. Electroceram. 19, 11 (2007)

38. W.L. Warren, G.E. Pike, K. Vanheusden, D. Dimos, B.A. Tuttle, J. Robertson, J. Appl. Phys. 79, 9250 (1996)

39. W. Zhu, I. Fujii, W. Ren, S. Trolier-McKinstry, J. Appl. Phys. 109, 064105 (2011)

40. M. Jain, S.B. Majumder, R.S. Katiyar, D.C. Agrawal, A.S. Bhalla, Appl. Phys. Lett. 81, 3212 (2002)

41. Y. Fan, S. Yu, R. Sun, L. Li, Y. Yin, K.-W. Wong, R. Du, Appl. Surf. Sci. 256, 6531 (2010)

42. M.W. Cole, P.C. Joshi, M.H. Ervin, M.C. Wood, R.L. Pfeffer, Thin Solid Films 374, 34 (2000)

43. J. Yang, X.J. Meng, M.R. Shen, J.L. Sun, J.H. Chu, J. Appl. Phys. 106, 094108 (2009)

44. L. Wu, Y.C. Chen, Y.P. Chou, Y.T. Tsai, S.Y. Chu, Jpn. J. Appl. Phys. 38, 5154 (1999)

45. K.M. Johnson, J. Appl. Phys. 33, 2826 (1962) 